\title{
Faculty Development in Student Learning Communities: Exploring the Vitality of Mid-Career Faculty Participants
}

\author{
Shari Ellertson \\ University of Wisconsin-Stevens Point \\ John H. Schuh \\ lowa State University
}

Student learning communities result in numerous benefits for students and institutions, but less is known about the influence of learning community participation on faculty renewal and development. This qualitative study examines mid-career faculty members' involvement in student learning communities to explore the degree to which the construct of vitality appropriatcly describes and illuminates their experiences. Findings suggest that lcarning communities foster vitality by serving as a boundary-spanning activity where faculty can merge various work interests, allowing them to engage in purposeful production and providing them with experiences that help generate feelings of energy, excitement, and engagement with their work.

id-career faculty appear to be at a point in their professional develop\& Taylor, 1996), and where it is reported that their research productivity as measured by published articles dips. These faculty members have been identified as having excellent potential for participation in student learning communities given their "stage in their careers" (Gabelnick, MacGregor, 
Matthews, \& Smith, 1990, p. 78) or levels of interest (Smith, 1988; Strommer, 1999). Blackburn (1985) found that research productivity over the faculty career follows a saddle-shaped curve, illustrating a dip in the mid-career. A rise, a peak, a fall, and then another rise characterize the general pattern of productivity across the career span. This pattern of productivity suggests that mid-career faculty development needs may be centered on providing opportunities for them to energize themselves and their careers by participating in new experiences. Student learning communities provide one such experience that may add robustness and energy to faculty careers.

At the core of the student learning community experience is the interaction of faculty and students working together to create learning environments. Smith, MacGregor, Matthews, and Gabelnick (2004) define learning communities as "a variety of curricular approaches that intentionally link or cluster two or more courses, often around an interdisciplinary theme or problem, and enroll a common cohort of students" (p. 67). Regardless of a learning community's structure, Shapiro and Levine (1999) assert that nothing can replace the active involvement and engagement of faculty in student learning communities.

Research on the influence of student learning communities is increasingly robust (see, for example, Epperson, 2000; Gabelnick et al., 1990; Goldberg \& Finkelstein, 2002; Goodsell Love, 1999; Huba, Ellertson, Cook, \& Epperson, 2003; Matthews, Snith, MacGregor, \& Gabelnick, 1997). Much of what is written about learning communities focuses on institutional outcomes (i.e., retention and graduation rates, financial gains, etc.) and student outcomes (i.e., retention, skill development, academic performance, etc.); however, little is known about the influence of learning community involvement on participating faculty. Although some have speculated that learning community involvement has far-reaching potential for influencing faculty renewal and development (Gabelnick et al., 1990; Matthews et al., 1997; Smith, 1988), evidence of this impact is largely anecdotal or underreported (MacGregor \& Smith, 2005). Further, Smith suggests that learning communities are particularly appealing to and have specific faculty development implications for mid-career faculty. We engaged in this study to explore the perceptions of mid-career faculty on the value of their participation in student learning communities.

While student learning communities have been employed to promote student success at major research universities (Pike, 1999; Pike, Schroeder, \& Berry, 1997), participating faculty may fall outside what would be considered a traditional career path in this context, and may even be "performing a counter-cultural, even revolutionary, act” (Golde \& Pribbenow, 2000, p. 38). 
According to the Boyer Commission (1998), many research universities commonly expect faculty to interact only rarely with undergraduate students; thus, those who do fall outside the traditional norms of the institution.

The need for this research stems from calls to further examine mid-career faculty and to use qualitative research to better understand faculty needs and values (Kalivoda, Sorrell, \& Simpson, 1994). Additionally, the learning communities "communities of practice" group from the American Association for Higher Education's 2002 assessment conference called for "case studies and personal narratives, especially ones about the changing faculty role and the effects of [student] learning communities on faculty" (J. O'Connor, personal communication, June 27, 2006).

The purpose of this exploratory study is to examine the degree to which the construct of vitality can appropriately describe and illuminate faculty experiences in student learning communities. The guiding question of the study is this: Do learning communities foster the vitality of participating mid-career faculty members?

\section{Theoretical Frameworks}

This study was situated within two main theoretical frameworks: faculty vitality as the driving content theory and constructivism as the guiding methodological theory. Vitality is a construct that is complex and not easily defined; however, it provides a more holistic exploration of faculty careers in that vitality includes but is not wholly expressed through productivity. Gooler (1991), for example, characterizes vital faculty as those

Who are reading books and other materials, who are still very interested in their teaching, who are productive in scholarly activities. These professors carry about them a certain excitement and enthusiasm for their work and for their colleagues and students. (p. 13)

Vitality, in its essence, appears to capture a spirit of engagement that faculty members have with their work. Baldwin (1990) observes,

Vital professors typically are individuals who challenge students academically and contribute to their overall development.... are curious and intellectually engaged.... enjoy the respect of their colleagues and are effective in the multiple roles of members of their academic profession.... grow personally and professionally throughout the academic carcer..." (p. 180) 
The ambiguous nature of vitality allows for its complexities to emerge. Vitality, because of its abstract and multiple meanings, can best be explored through the inductive process afforded by a constructivist qualitative approach and phenomenological methodology. The basic tenet of constructivism is the inexistence of a universal truth waiting to be discovered; rather, constructivists argue that knowledge is created through active engagement of individuals with each other and their environments (Crotty, 1998). Phenomenology is concerned with the meanings that individuals ascribe to their experiences (Crotty, 1998). Furthermore, phenomenology lends itself to multiple realities, where different (and even divergent) constructions are considered meaningful (Schwandt, 1998). Because the aim of the inquiry is to understand the lived experiences and realities of mid-career faculty members, the methodology of this study is firmly grounded.

\section{Student Learning Communities at lowa State University}

Iowa State University (ISU) is a large, research-extensive institution. Student learning communities (hereafter referenced as learning communities) began at ISU in 1995 as a grassroots movement driven by faculty and staff members who wanted to improve student learning. The learning communities were not centrally administered (Huba et al., 2003). However, they grew in number and eventually became institutionalized as the result of a three-year internal presidential grant from 1998-2001. During that time, the number of learning communities grew from 23 to 48 , and student participation nearly doubled, going from 1,114 to 2,103 participants (Huba et al., 2003). In 2005, more than $50 \%$ of first-year full-time students participated in a learning community. Although most ISU learning communities are geared toward first-year students, some sophomore, transfer, and other upper-level communities have developed (Huba et al., 2003). In addition, most learning communities at ISU are discipline specific (i.e., agronomy, computer engineering, biology, etc.) and have qualities of three commonly used models: the linked courses model, clustered courses model, and freshman interest groups model (Matthews et al., 1997).

\section{Method}

We used criterion-based selection to identify participants for this study. All participants must have held at least the rank of associate professor with tenure; have had more than five years remaining to retirement; have been involved with a learning community during the current academic year; and 
have had a minimum of one semester of involvement as a coordinator or course instructor for a first-year learning community. The first two criteria are consistent with definitions of a mid-career faculty member. The third criterion was to ensure that participants currently were engaged in learning community work. The final criterion was essential for identifying faculty members who have experienced at least one full unit of the academic calendar-a semester - with a first-year learning community. These faculty fall outside what may be considered traditional norms of a research institution and thus provide the opportunity to explore the construct of vitality with "faculty cohorts outside the traditional career path" (Kalivoda et al., 1994, p. 269). Our selection procedure resulted in 10 participants from different learning communities and various academic disciplines.

Consistent with qualitative inquiry, a criterion for determining the adequacy of sample size is the attainment of information redundancy, which occurs when "no new information is forthcoming from newly sampled units" (Lincoln \& Guba, 1985, p. 202). Informational redundancy as we achieved in this study also contributes to the overall trustworthiness of the research, which is discussed next.

We utilized three qualitative methods of data collection in this study: phenomenologically based interviews, document analysis, and observations. We conducted in-depth interviews in 75- to 90-minute timeframes using a semi-structured interview protocol. We scheduled one participant initially for an interview as a pilot study to test the protocol; after this interview, the protocol was refocused. All interviews were audiotaped and transcribed within one month. We sent transcripts to participants by email to provide them an opportunity to review transcripts for accuracy and make clarifications or corrections. This is one way of conducting member checking (Lincoln \& Guba, 1985), which also contributes to the trustworthiness of the study. Two participants responded with minor corrections and/or clarifications to their transcripts. We sent two additional questions to all participants as a follow-up via email.

We analyzed the curricula vitae of participants in relation to their careers and professional experiences. Because examining learning community participation as part of the academic career was central to this study, curricula vitae provided the kind of documentation that would illuminate participants' careers from their perspectives. We also relied on documentation from the ISU learning communities office to compile descriptive information, faculty involvement data, participation rates, and so forth.

As part of an "emergent design" (Lincoln \& Guba, 1985), we added participant observations as a third phase of data collection after the first two 
phases were completed. Observations provided an opportunity to see the faculty "in action" with the students in their learning community. Due to the timing of the observations, only two faculty members had relevant learning community events. Thus, observations were conducted with these two faculty members for approximately one hour (or the duration of the activity) in a learning community class and at a learning community picnic, respectively. We debriefed with the faculty member immediately following the activity to discuss it, ask follow-up questions, and review field notes for accuracy and completeness.

We analyzed data continuously throughout the study using the constant comparative approach that "combines inductive category coding with a simultaneous comparison of all social incidents observed and coded" (LeCompte \& Preissle, 1993, p. 256). Inductive category coding, therefore, emerges from the data as opposed to the data being analyzed by predetermined categories imposed by the researcher. Various strategies assisted the data analysis process, such as analytic memos and an interview log, which provided one mechanism for immediate reflection on each interview. During an initial reading of interview transcripts, we highlighted passages of interest and items that were particularly emphasized by respondents. From this, we identified emerging patterns (e.g., working codes) and working hypotheses and filtered those back into the study. We continually refined the themes and then used categorical clustering to establish final themes.

In addition to informational redundancy and member checking (as previously discussed), we employed several other strategies to establish the trustworthiness of the study. Triangulation of sources and methods and peer debriefing with a collengue who is familiar with both learning communities and qualitative inquiry contributed to the credibility of the findings and interpretations. Although generalizability is not a goal of qualitative research, "thick descriptions" can assist readers in determining the potential transferability of the information to other settings. Thus, we have attempted to provide thick descriptions through detailed description of our method and use of participants' quotes in our findings. In addition, we strengthened the dependability (i.e., reliability) of our study by selecting appropriate methodology, utilizing feedback from colleagues and peers in the development of the study, and pilot testing the interview protocol. Finally, our audit trail consisting of detailed notes, interview tapes, and other data forms (as well as our use of a peer debriefer) aid in the confirmability of our study; that is, the degree to which the data support the conclusions. 


\section{Findings}

Vitality was selected as a lens through which to examine faculty participation in learning communities because it had the potential to address faculty careers holistically rather than simply looking at productivity as measured by the number of research publications produced. Three main themes emerged from the data: energy, excitement, and engagement; merging of work interests; and purposeful production.

\section{Energy, Excitement, and Engagement}

Faculty in this study identified feelings of energy, excitement, and overall engagement with their work when interacting with students. Although the energy, excitement, and engagement seem characteristic of their work with students in general, participating in learning communities provided opportunities for interacting with students, which appears to serve as an additional stimulus for vitality. According to Joseph (all names are pseudonyms), "Any time I'm interacting with students, I find it to be... exciting and revitalizing.... And the advantage to learning communities is it provides more opportunities."

Likewise, Meredith demonstrated excitement and energy when gathering with learning community students for a picnic. While sitting on the ground in a circle with students and eating hamburgers, Meredith conversed informally with various students about everything from their summer living arrangements to the latest campus news. She was clearly comfortable with students in this informal setting, and they appeared comfortable with her as well. For the more "formal" portion of the picnic, Meredith asked students to take turns discussing their summer work plans as well as what they planned to do for fun. During the debriefing after the event, Meredith commented that the picnic was a good opportunity for her to reconnect with the learning community, say goodbye for the summer, and have some closure with the group. She viewed the "formal" portion of the picnic as a way to integrate an academic topic (i.e., summer work plans) into the conversation as well as to show the students that she cared about them by asking about their plans for fun. Meredith characterized the learning community as fostering one of her goals, which is to "make an impact in people's lives, to help students develop into professionals and good citizens." Thus, the learning community provided an environment where Meredith could interact with students in a way that was energizing and exciting for her.

Jack exhibited energy, excitement, and engagement with his learning community during their course. Jack was presenting information to the class 
and a student challenged him, asking, "What is the point of knowing this?" Jack responded with, "That's a good question," and then provided a rationale for why it was important they learn about the topic at hand. After Jack finished talking, another student interjected a very concise and well-thoughtout point of view on why they were learning about the topic. To this, Jack responded, "That's a better response than the one I gave." Rather than being defensive or feeling "upstaged" by the student, Jack delighted in it, saying in our debriefing session, "He [the student] connected two things and that's great!" He said the apparent sparkle in his eye in the learning community class derived from the pleasure he feels when students make gains. The learning community class provided the types of interactions where he can see student gains quickly and immediately.

Finally, Kent said that he feels most active, alive, and engaged with his work when he is teaching first-year students, some of whom are in the learning community. He shared,

Here is where I would disagree with many of my counterparts in other programs that think that it's a waste of time to work with freshmen; that's when I'm engaged. That's when I'm really alive.... I love first term, new 18 year olds. I love exciting them about where they're going, the challenges in their carcer, the controversies in their career, and the basic sciences in their career so that when I get done I hope they know a lot more about [not only the subject] but also a lot more about what they're going to be and what they're going to do.

Kent contrasted this experience with a time in his career when he felt disengaged. In other words, he was able to discuss vitality by recalling a story that illustrates an opposite experience. He said,

And then you get into that mid-career thing where you're getting onto more committees and activities and you begin to feel a little bit disengaged. I know there was a time when I was on about five university committees, five or six college committees and seven or eight, nine at one time in my department and I felt like I wasn't being productive. I felt like I was spinning my wheels. I wasn't spending enough time on my classes. I was doing things that were important for students and committees, but boy, it was all committce work and 1... became somewhat, I thought, disengaged... [I have felt I am] kind of refocusing again the last few years. And so I really feel, especially [in] my freshman class, I just feel like I'm 100\% there again. 
Kent's experiences are similar to Gooler's (1991) assertion that one can identify experiences and characteristics of vitality by identifying opposite experiences and characteristics. For Kent, as with other faculty in this study, the learning community served as a venue for helping students; through helping students, he felt energy, excitement, and engagement with his work. In short, the learning community appears to provide Kent and other faculty with opportunities to experience vitality.

Energy, excitement, and engagement with one's work appear to be consistent with mid-career faculty development needs and vitality as presented in the literature. Cytrynbaum, Lee, and Wadner (1982) propose that mid-career faculty may experience "professional or personal withdrawal" (p. 16); therefore, feeling energy, excitement, or engagement with one's work seems to be opposite of some of the negative manifestations of mid-career faculty development. Clark, Corcoran, and Lewis (1986) found that highly active (i.e., vital) faculty had high self-ratings of energy. Although faculty in this study were not rating their energy levels, they described experiencing energy as characteristic of times in their careers when they felt most vital.

\section{Merging of Work Interests}

Faculty in this study described a merging of work interests that occurred for them as participants in the learning community. This is a second manifestation of vitality. Analysis of their curricula vitae revealed that most faculty identified learning community work as a separate item on their vita, and learning community work crossed all categories of the vita. For example, learning community work appeared under the categories of teaching, grants, service, awards, and scholarship/publications on vitae. Learning community work was not treated indiscriminately or as inferior; rather, it was presented purposefully and often given particular emphasis (i.e., a category of work unto itself).

The boundary-spanning nature of learning communities was further evident in faculty stories. Faculty indicated that experiences during which their work interests come together provided them with feelings of being active and alive in their work (i.e., vital). Nancy described this merging of interests as "being in the zone." According to her,

1 think when 1 was streamlined, when my research and my teaching and my outreach was [sic] in one subject area, where all I had to worry about was [my area of expertise]. I think that was when I was most alive. I think being focused. 
Nancy's learning community involvement drew together various aspects of her work, including teaching, service, and scholarship. Thus, her learning community provided her with the kind of opportunity that she described as fostering her vitality.

Similarly, Byron and Joseph explained that their merging work interests provided them with experiences in which they felt particularly vital. Byron experienced enjoyment at being able to share his expertise through teaching. He said, "The things that have most engaged me is where I can provide people with my technical knowledge and [do it through] teaching." It is not just the delivery of the content that made Byron feel active and alive, but also the creativity of determining a way to share his knowledge that sparked his experience of "aliveness" (i.e., vitality). He shared, "giving them my perspective of [the topic] so they get the technical knowledge but I get to package that technical knowledge the way that I think will have the most meaning and impacting value to them." The creative challenge inherent in merging his work interests (in this case, his technical expertise and his teaching of it) was stimulating. Certainly, learning communities can provide a creative outlet that allows for the merging of expertise and teaching, particularly because of the course-based and teaching-intensive nature of them.

Joseph specifically discussed his learning community as an environment in which his various teaching interests and his passion for his discipline merged. He said,

I would say in some ways the [learning community's service-learning project] really sort of weaves together all of the things I'm interested in.... [It] sort of brings all those pieces together into... one activity, one thing. I basically feel like I'm doing what I want to do, what I'm interested in, and what I think I'm good at. It's a pleasure to do things that you feel like "yeah, I can do that pretty well." It's frustrating to try and do things that you think "really l'm not that great at it."

Thus, Joseph derived pleasure and satisfaction from doing activities that wove together his interests and areas of work.

Learning communities can provide a boundary-spanning experience in which various aspects of faculty work can be woven together. Moreover, faculty in this study described the merging of work interests as characteristic of times when they feel most vital. While the blurring of boundaries may be common among mid-career faculty in general, learning communities seem to provide an environment where merging work interests can readily occur. 


\section{Purposeful Production}

Faculty in this study described their learning community involvement as fulfilling larger overarching purposes than the outcomes realized by them or their students. They viewed their participation also as beneficial to the institution, their disciplines and departments, and even professional societies; thus, they were engaging in "purposeful production." Clark and Corcoran (1985) described vitality as "those essential, yet intangible, positive qualities of individuals and institutions that enable purposeful production" (p. 3). Essentially, purposeful production is the positive interplay between individuals and institutions, and faculty in this study viewed their learning community involvement as mutually beneficial work.

The learning community can provide experiences in which faculty feel that they are working with others toward a common purpose. According to Sharon, her "peak experiences," or experiences where she has felt the most active and alive, included the following:

Just really getting a chance to talk with people on some of those overarching ideas, on where do we want to go, how do we want to get there? Having just occasionally the sense that we are working together to do something important. I think that some of the team meetings I've been involved in-in terms of developing a learning community or developing [a related program]-have been really great experiences along those lines.... I think it's just having all those points of view that you get to see and get to have a sense that with all these different points of view, you are working together for some common purpose. That you are working effectively for a common purpose.

Having a shared purpose, therefore, helped Sharon feel vital. For others, they hoped students would have positive feelings about and experiences within their departments. Harry concluded,

I guess I feel good about it [the learning community] if the students come away from it with a positive feeling about the department.... I don't want them to leave because they're misinformed, let's put it that way."

In essence, the faculty viewed the learning community experience as beneficial for the students and the department.

Finally, some faculty characterized learning communities as having benefits that stretch beyond the institution, for example, to professional discipli- 
nary associations. Mark said his learning community has positively impacted both his association and his department. He shared,

I knew at least from working with constituents like industry that we weren't meeting their needs as far as the number of [majors] going out the door. So I thought if I can do something [the learning community] to increase our numbers, help our department because we needed to have certain numbers, and also help our professional society to meet their numbers, I feel like I'm really accomplishing something.

Overall, faculty members regard the learning community as helping them to meet purposes that are larger than themselves or their students; it also helps the institution, their departments, and their professional associations.

Vitality can occur when there is positive interplay between the faculty experience and broader interests, such as those of the institution (Bland \& Schmitz, 1990; Clark \& Corcoran, 1985). At Iowa State University, several institutional gains from learning communities, such as increased retention and graduation rates and financial gains, are reported (Epperson, 2000; Huba et al., 2003). Because faculty in this study indicated experiencing positive outcomes and gaining satisfaction from engaging in "purposefully productive" work, one could infer that the faculty and the institution positively intersect in learning communities.

\section{Discussion}

The extent to which learning communities provide an environment that fosters faculty vitality was the primary question explored in this study. Experiences described by faculty as making them feel vital match the types of experiences that learning communities can provide, suggesting that learning communities, in fact, can promote faculty vitality. One way in which learning communities foster vitality is by serving as a boundary-spanning activity that helps faculty bring together various elements of their work. Lamber et al. (1993) found that "the boundaries between the professional roles of teaching, research, and service become less clear" (p. 24) as faculty progress into their mid-career. Thus, learning communities may serve a developmental need of mid-career faculty, suggesting that they are an appropriate development strategy for mid-career faculty as Smith (1988) and Strommer (1999) speculated. Moreover, the boundary-spanning aspect of learning communities fosters the merging of work interests that faculty described as fostering their vitality. 
Another important aspect of vitality is that it is contextual to the particular institutional setting. Several researchers suggest that vitality can occur when faculty and institutional interests intersect in a positive way (Bland \& Schmitz; 1990; Clark \& Corcoran, 1985; Gooler, 1991). Faculty in this study described their learning community involvement as fulfilling larger, overarching purposes than the outcomes realized by them or their students. They also regarded their learning community work as beneficial to the institution, their disciplines and departments, and even their professional organizations.

Finally, faculty in this study experienced what Clark and Lewis (1985) call the "dimension of vitality variously termed enthusiasm, energy, or esprit" (p. 249). When faculty discussed work experiences that make them feel active, alive, and engaged (i.e., vital), they identified a sense of energy, excitement, and engagement deriving from their work with students. Their learning community involvement, because it is student intensive, stimulated their energy, excitement, and engagement. Thus, because learning communities provide a venue that is rich in opportunities for student interaction, they provide an environment that fosters vitality.

\section{Recommendations and Conclusions}

Should mid-career faculty be tapped to participate in programs such as learning communities? The findings of this research suggest they should because of the potential for faculty development and the positive influence on faculty vitality. Faculty developers should identify nontraditional faculty development opportunities, such as learning communities, and make efforts to connect mid-career faculty with these programs. Faculty development benefits also are noted in related initiatives, such as first-year seminars (Barefoot, 1993) and living-learning programs (Stassen, 2000). Often, these types of programs may be coordinated by or offered in concert with student affairs, thus providing an opportunity for the faculty developer to serve as a critical link between faculty and student affairs colleagues. This outreach may be especially important in cases where teaching and learning centers are not involved directly in the student learning communities or related programs since faculty development efforts in these programs may be limited or obscured.

Student learning communities (and related programs) also provide fertile grounds for additional research on faculty development. For example, it would be instructive to know if learning communities help meet faculty development needs for faculty at different stages of their careers. Knowing this 
could potentially help shape various roles in learning communities for early-, mid-, and late-career faculty. For instance, is it possible that latecareer faculty members may be interested in mentoring roles (which may meet their developmental needs) and early-career faculty members may be interested in scholarship opportunities in learning communities, just as the creative aspects of learning communities seem to appeal to mid-career faculty? Knowing more about the faculty development potential of learning communities for faculty at various career stages makes sense not only for development purposes but also for the purposes of identifying and recruiting faculty participants.

Faculty developers also can extend the understanding of vitality by researching its meanings and manifestations in their institutional contexts. This understanding may provide insights into the types of activities that faculty find the most energizing and revitalizing. Subsequently, faculty developers can design additional development efforts aimed at enhancing faculty vitality.

After faculty are connected with opportunities such as learning communities, we cannot assume they will automatically reap the development benefits. Faculty developers can make intentional and systematic efforts to maximize the benefits for participating faculty by providing them with adequate resources, information, and reflective experiences. In essence, we need to be in the field with our faculty to attend to their development needs as they arise. Perhaps Joseph said it best when he described how learning communities create opportunities and experiences that otherwise would not be naturally occurring:

You've got to sort of create an environment where they [unique experiences] can happen. And learning communities, when they're done well, when they're done properly, ... create those kind of environments... it's like bird watching or something. I mean, you have to be out there. You're not going to see a Cooper's hawk every day, but you know, sometimes you do, and you know, it's cool when it happens.

As faculty development professionals, we too must be "out there" for our faculty, identifying and creating opportunities for them to remain engaged in their work and enhance their feelings of vitality. 


\section{References}

Baldwin, R. G. (1990, March/April). Faculty vitality beyond the research university: Extending a contextual concept. Journal of Higher Education, 61(2), 160-180.

Barefoot, B. O. (Ed.). (1993). Exploring the evidence: Reporting outcomes of freshman seminars (Monograph No. 11). Columbia, SC: University of South Carolina, National Resource Center for the First-Year Experience and Students in Transition.

Blackburn, R. T. (1985). Faculty career development: Theory and practice. In S. M. Clark \& D. R. Lewis (Eds.), Faculty vitality and institutional productivity: Critical perspectives for higher education (pp. 55-85). New York, NY: Teachers College Press.

Bland, C. J., \& Schmitz, C. C. (1990). An overview of research on faculty and institutional vitality. In J. H. Schuster, D. W. Wheeler, \& Associates, Enhancing faculty careers: Strategies for development and renewal (pp. 41-61). San Francisco, CA: Jossey-Bass.

Boyer Commission on Educating Undergraduates in the Research University. (1998). Reinventing undergraduate education: A blueprint for America's research universities. Retrieved June 24, 2006, from the Stony Brook University web site: http://naples.cc.sunysb.edu/Pres/boyer.nsf

Clark, S. M., \& Corcoran, M. (1985). Individual and organizational contributions to faculty vitality: An institutional case study. In S. M. Clark \& D. R. Lewis (Eds.), Faculty vitality and institutional productivity: Critical perspectives for higher education (pp. 112-138). New York, NY: Teachers College Press.

Clark, S. M., Corcoran, M., \& Lewis, D. R. (1986, March/April). The case for an institutional perspective on faculty development. Journal of Higher Education, 57(2), 176-195.

Clark, S. M., \& Lewis, D. R. (1985). Implications for institutional response. In S. M. Clark \& D. R. Lewis (Eds.), Faculty vitality and institutional productivity: Critical perspectives for higher education (pp. 247-256). New York, NY: Teachers College Press.

Crotty, M. (1998). The foundations of social research: Meaning and perspective in the research process. Thousand Oaks, CA: Sage.

Cytrynbaum, S., Lee, S., \& Wadner, D. (1982). Faculty development through the life course: Application of recent adult development theory and rescarch. Journal of Instructional Development, 5(3), 11-22.

Epperson, D. L. (2000). Report on onc-ycar and two-ycar university retention rates associated with first-year participation in a lcarning community at lowa State University: Ames, IA: lowa State University, Learning Communities. 
Frost, P. J., \& Taylor, M. S. (Eds.). (1996). Rhythms of academic life: Personal accounts of careers in academia. Thousand Oaks, CA: Sage.

Gabelnick, F., MacGregor, J., Matthews, R. S., \& Smith, B. L. (1990). New directions for teaching and learning: No. 41. Learning communities: Creating connections among students, faculty, and disciplines. San Francisco, CA: Jossey-Bass.

Goldberg, B., \& Finkelstein, M. (2002, Summer). Effects of a first-semester learning community on nontraditional technical students. Innovative Higher Education, 26(4), 235-249.

Golde, C. M., \& Pribbenow, D. A. (2000, January/February). Understanding faculty involvement in residential learning communities. Journal of College Student Development, 41(1), 27-40.

Goodsell Love, A. (1999). What are learning communities? In J. H. Levine (Ed.), Learning communities: New structures, new partnerships for learning (pp. 1-8). Columbia, SC: University of South Carolina, National Resource Center for the First-Year Experience and Students in Transition.

Gooler, D. D. (1991). Professorial vitality: A critical issue in higher education. DeKalb, IL: LEPS Press.

Huba, M. E., Ellertson, S., Cook, M. D., \& Epperson, D. (2003). Assessment's role in transforming a grass-roots initiative into an institutionalized program: Evaluating and shaping learning communities at lowa State University. In J. MacGregor (Ed.), Doing learning community assessment: Five campus stories (pp. 21-47). Olympia, WA: The Evergreen State College, Washington Center for Improving the Quality of Undergraduate Education.

Kalivoda, P., Sorrell, G. R., \& Simpson, R. D. (1994, Summer). Nurturing faculty vitality by matching institutional interventions with career-stage needs. Immovative Higher Education, 18(4), 255-272.

Lamber, J., Ardizzone, T., Dworkin, T., Guskin, S. L., Olsen, D., Parnell, P., et al. (1993). A "community of scholars": Conversations among mid-career faculty at a public research university. In D. L. Wright \& J. P. Lunde (Eds.), To improve the academy: Vol. 12. Resources for faculty, instructional, and organizational developmemt (pp. 13-26). Stillwater, OK: New Forums Press.

LeCompte, M. D., \& Preissle, J. (1993). Ethnography and qualitative design in educational rescarch (2nd ed.). San Diego, CA: Academic Press.

Lincoln, Y. S., \& Guba, E. G. (1985). Natturalistic inquiry. Newbury Park, CA: Sage.

MacGregor, J., \& Smith, B. L. (2005, May/June). Where are learning communities now? National leaders take stock. About Campus, 10(2), 2-8. 
Matthews, R. S., Smith, B. L., MacGregor, J., \& Gabelnick, F. (1997). Creating learning communities. In J. G. Gaff, J. L. Ratcliff, \& Associates, Handbook of the undergraduate curriculum: A comprehensive guide to purposes, structures, practices, and change (pp. 457-475). San Francisco, CA: Jossey-Bass.

Pike, G. R. (1999, May/June). The effects of residential learning communities and traditional residential living arrangements on educational gains during the first year of college. Journal of College Student Development, 40(3), 269-284.

Pike, G. R., Schroeder, C. C., \& Berry, T. R. (1997, November/December). Enhancing the educational impact of residence halls: The relationship between residential learning communities and first-year college experiences and persistence. Journal of College Student Development, 38(6), 609-621.

Schwandt, T. A. (1998). Constructivist, interpretivist approaches to human inquiry. In N. K. Denzin \& Y. S. Lincoln (Eds.), The landscape of qualitative researcl: Theories and issues (pp. 221-259). Thousand Oaks, CA: Sage.

Shapiro, N. S., \& Levine, J. H. (1999). Creating learning communities: A practical guide to winning support, organizing for change, and implementing programs. San Francisco, CA: Jossey-Bass.

Smith, B. L. (1988). The Washington Center: A grass roots approach to faculty development and curricular reform. In J. G. Kurfiss (Ed.), To improve the academy: Vol. 7. Resources for student, faculty, and institutional development (pp. 165-177). Stillwater, OK: New Forums Press.

Smith, B. L., MacGregor, J., Matthews, R. S., \& Gabelnick, F. (2004). Learning communities: Reforming undergraduate education. San Francisco, CA: Jossey-Bass.

Stassen, M. L. A. (2000). "It's hard work!": Faculty development in a program for first-year students. In M. Kaplan \& D. Lieberman (Eds.), To improve the academy: Vol. 18. Resources for faculty, instructional, and organizational development (pp. 254-277). Bolton, MA: Anker.

Strommer, D. W. (1999). Teaching and learning in a learning community. In J. H. Levine (Ed.), Learning communities: New structures, new partnerships for learning (pp. 39-49). Columbia, SC: University of South Carolina, National Resource Center for the First-Year Experience and Students in Transition. 